\title{
Effect of Sintering on the Marginal and Internal Fit of CAD/CAM-fabricated Zirconia Frameworks
}

Jun KUNII, Yasuhiro HOTTA, Yukimichi TAMAKI, Atushi OZAWA, Yukitaka KOBAYASHI, Akihiro FUJISHIMA, Takashi MIYAZAKI and Toshihisa FUJIWARA

Department of Oral Biomaterials and Technology, School of Dentistry, Showa University, Japan, 1-5-8 Hatanodai, Shinagawaku, Tokyo 142-8555, Japan

Corresponding author, Jun KUNII; E-mail: j-kunii@dent.showa-u.ac.jp

Received February 7, 2007/Accepted June 17, 2007

\begin{abstract}
The aim of this study was to investigate the effect of post-machining sintering on marginal and internal fit of CAD/CAMfabricated zirconia frameworks. Single crown copings (A: abutment), three-unit bridge frameworks (APA, P: pontic), four-unit bridge frameworks (APPA), and five-unit bridge frameworks $\left(\mathrm{A}_{1} \mathrm{P}_{1} \mathrm{~A}_{2} \mathrm{P}_{2} \mathrm{~A}_{3}\right)$ were fabricated with raw-stage zirconia blanks using a commercial CAD/CAM system (KATANA®, Noritake Dental Supply Co. Ltd., Aichi, Japan). Crown copings and frameworks were cemented to their respective master abutment models, and thickness of the cement layer was measured at specific measuring points. Marginal and internal fit of both APA and APPA were within clinical acceptance. However, the marginal gap and thickness of the cement layer on the axial surface of the pontic side of APA and APPA were slightly higher than those of the non-pontic side. As for the marginal gap of $\mathrm{A}_{1} \mathrm{P}_{1} \mathrm{~A}_{2} \mathrm{P}_{2} \mathrm{~A}_{3}$ framework, it was superior to those of APA and APPA because the center abutment supported the framework to prevent distortion.
\end{abstract}

Keywords: Zirconia ceramics, CAD/CAM system, Framework

\section{INTRODUCTION}

For the dual purpose of meeting patient expectations for good esthetic results and circumventing allergy concerns arising from contact with metallic frameworks ${ }^{1-8)}$, all-ceramic restorations have become both a necessary alternative as well as a preferred choice. Against this background, all-ceramic fixed partial dentures (FPDs) using CAD/CAM-fabricated alumina and zirconia frameworks are now available and aplenty in clinics. In particular, zirconia ceramics seem especially promising for use in long frameworks because of their high fracture toughness ${ }^{9-11)}$.

Currently, three types of zirconia blanks are available for the CAD/CAM system. One is the completely sintered dense blanks for direct machining by CAD/CAM. The other two types of blanks for CAD/ CAM fabrication require post-machining sintering to obtain final products with sufficient strength. They are namely blanks at the green stage or pre-sintered blocks, while another type are blanks at the raw stage in the form of a partially stabilized zirconia powder mixed with a binder. Completely sintered blanks are advantageous for avoiding undesirable dimensional changes - a result of sintering shrinkage that occurs during post-machining heat treatments; however, they have the disadvantage of damaging tools and causing chip formation during machining. On the other hand, pre-sintered blanks are advantageous for easy machining without damaging tools and causing chip formation. However, owing to the large sintering shrinkage that occurs during post-machining heat treatments, it is necessary to correct the accompanying changes in framework dimensions.
Marginal fit plays an indisputably central role in the clinical success of restorations ${ }^{12,13}$. On this score, many studies have focused on investigating the fit of zirconia frameworks fabricated with the different $\mathrm{CAD} / \mathrm{CAM}$ systems currently available in the market. Hertlein et al. reported that three-unit bridges (APA, A: abutment, P: Pontic) and four-unit bridges (AAPA) fabricated by the Lava ${ }^{\circledR}$ system that machined green-stage blanks with post-machining sintering showed good fit ${ }^{14)}$. Similarly, Reich et al. reported that three-unit bridges (APA) fabricated by both the Digident $^{\circledR}$ and Lava ${ }^{\circledR}$ systems showed good fit ${ }^{15)}$. On the other hand, using completely sintered dense blanks, Tinschert et al. reported on acceptable marginal fit of three-unit bridges (APA), four-unit bridges (APPA), and five-unit bridges (APPPA) fabricated by the DCS ${ }^{\circledR}$ system $^{16)}$.

As for the sintering shrinkage of pontics, it should also be taken into account as it might affect the marginal and internal fit of the abutment of bridges. However, to date, reports on average marginal gap did not consider the marginal gaps of either the pontic or non-pontic side - which meant that the effect of post-machining sintering on the overall fit of framework to the abutment has not been clarified yet ${ }^{14,15,16)}$. In this study, therefore, we sought to investigate the effect of post-machining sintering on the overall fit of $\mathrm{CAD} / \mathrm{CAM}$-fabricated restorations by taking into consideration the marginal gaps of both the pontic and non-pontic sides.

In view of the abovementioned study objective, standardized models for single crown copings (A), three-unit bridge frameworks (APA), four-unit bridge frameworks (APPA), and five-unit bridge frameworks 
$\left(\mathrm{A}_{1} \mathrm{P}_{1} \mathrm{~A}_{2} \mathrm{P}_{2} \mathrm{~A}_{3}\right)$ were prepared. Using a recently developed commercial CAD/CAM system (KATANA ${ }^{\circledR}$, Noritake Dental Supply Co. Ltd., Aichi, Japan), zirconia copings and frameworks were fabricated with rawstage blanks followed by post-machining sintering. Marginal and internal fit of the copings and frameworks on the abutment of each model were evaluated, and then compared with the cement space of both pontic and non-pontic sides.

\section{MATERIALS AND METHODS}

\section{Master abutment and models}

Figure 1 illustrates the shape and dimension of the master abutment. The marginal part was fixed with these dimensions: $10 \mathrm{~mm}$ diameter, $5 \mathrm{~mm}$ axial height, $10 \%$ axial taper, and 1-mm-wide shoulder. Master abutments were prepared by $\mathrm{NC}$ machining using stainless steel (SUS304). Prepared master abutments were then fixed on a metal plate using screws to prepare the master models for a single crown (A), a three-unit bridge framework (APA), a four-unit bridge framework (APPA), and a five-unit bridge framework $\left(\mathrm{A}_{1} \mathrm{P}_{1} \mathrm{~A}_{2} \mathrm{P}_{2} \mathrm{~A}_{3}\right)$ (Figs. 2 and 3$)$.

Impressions of each model (A, APA, APPA, and $\left.\mathrm{A}_{1} \mathrm{P}_{1} \mathrm{~A}_{2} \mathrm{P}_{2} \mathrm{~A}_{3}\right)$ were taken using a silicon impression material (Duplicone, Shofu Inc., Kyoto, Japan). A dental stone (MILLENNIUM, Shimomura Gypsum Inc., Saitama, Japan) was then cast in the impressions to produce stone models.

\section{Fabrication of copings and frameworks}

A commercial dental CAD/CAM system, KATANA ${ }^{\circledR}$, was used to fabricate the zirconia copings and frameworks used in this study.

Stone models of the coping (A) and frameworks (APA, APPA, and $\mathrm{A}_{1} \mathrm{P}_{1} \mathrm{~A}_{2} \mathrm{P}_{2} \mathrm{~A}_{3}$ ) were scanned using the measuring apparatus. Scanned data were then converted into CAD data. Copings for all-ceramic crowns

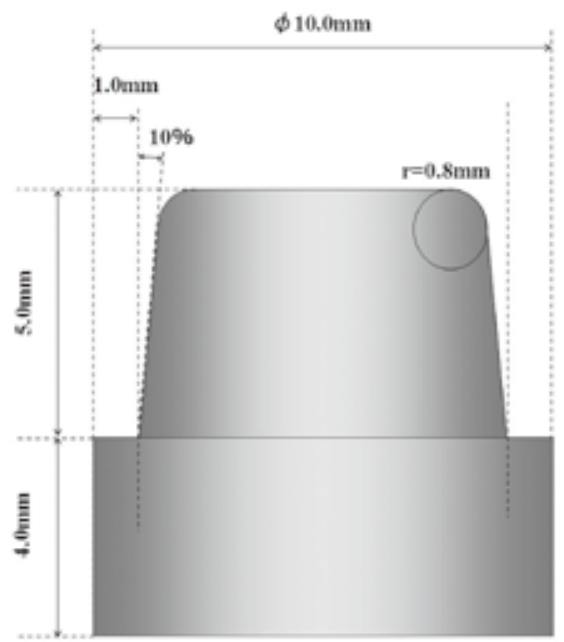

Fig 1. Dimensions of the master abutment. and frameworks for all-ceramic fixed partial dentures were designed using the CAD software. Sizes of all machined products were designed to be 21\% larger than those of the stone models with due consideration of sintering shrinkage. For the CAD/CAM system used in this study, the amount of cement space at the margin, axial and occlusal surfaces could be deter-

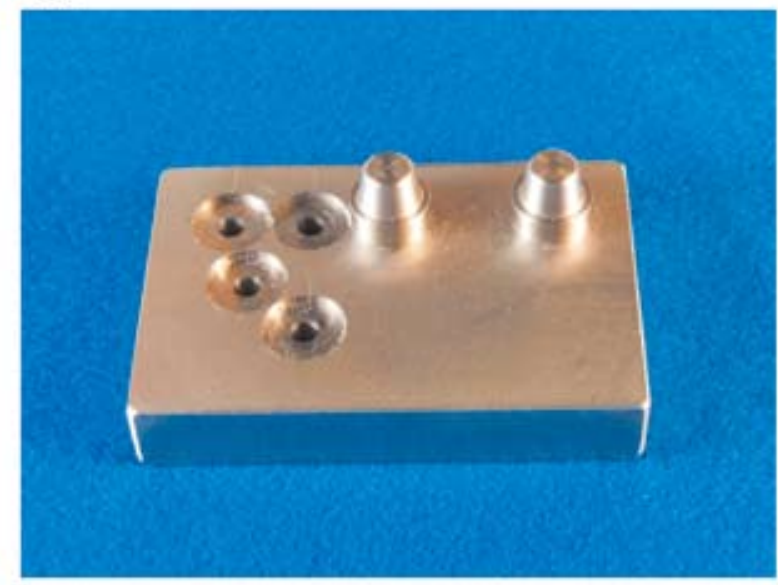

Fig 2. Model of the three-unit bridge (APA).

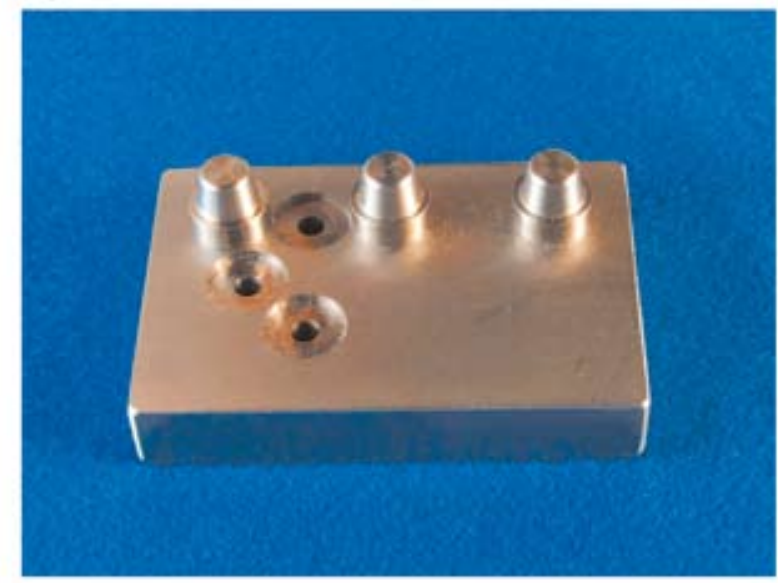

Fig 3. Model of the five-unit bridge $\left(\mathrm{A}_{1} \mathrm{P}_{1} \mathrm{~A}_{2} \mathrm{P}_{2} \mathrm{~A}_{3}\right)$.

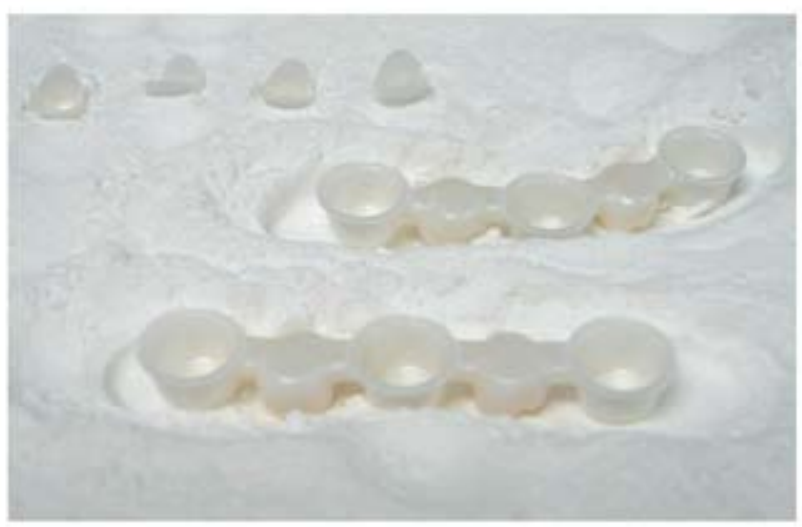

Fig 4. Frameworks seated on zirconia powder during the post-machining sintering process in a furnace. 


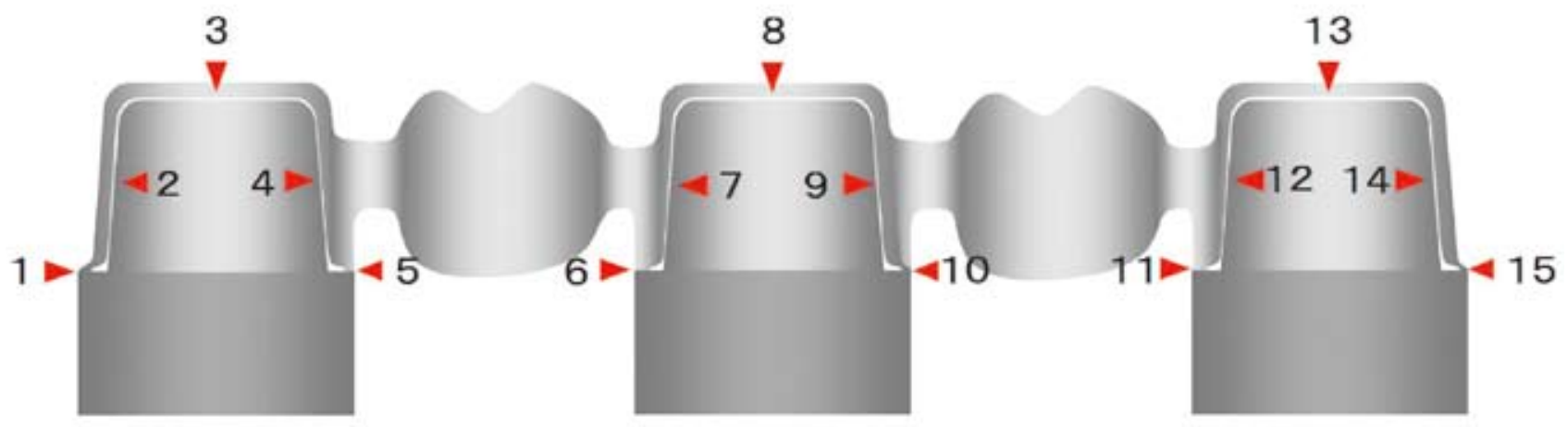

\section{single crown (A)}

\section{3-, 4-unit bridge (APA), (APPA)}

\section{5-unit bridge $\left(A_{1} P_{1} A_{2} P_{2} A_{3}\right)$}

Fig 5. Measurement points.

mined independently when designing the coping and frameworks. No cement space was included for the margin, and $50 \mu \mathrm{m}$ was used for the axial and occlusal surfaces of the abutment. Thickness of the frameworks was fixed at $0.5 \mathrm{~mm}$, and all pontics were designed to be of the same dimensions.

Design data were converted into processing data and sent to the processing machine. Designed copings and frameworks were milled with tungsten carbide burs of $1.3 \mathrm{~mm}$ diameter from raw-stage zirconia blanks of partially stabilized zirconia powder (95\% $\mathrm{ZrO}_{2}$, stabilized by $\left.5 \% \mathrm{Y}_{2} \mathrm{O}_{3}\right)$ mixed with a binder. Fabricated copings and frameworks were seated on zirconia powder sprayed on a tray. At this juncture, the occlusal surfaces of the copings and frameworks were placed facing down to be in slight contact with the zirconia powder (Fig. 4). Copings and frameworks were heated up to $500^{\circ} \mathrm{C}$ to vaporize the binder, then continuously sintered at $1,400^{\circ} \mathrm{C}$ using a sintering furnace.

\section{Measurement of marginal and internal gaps}

Completed zirconia copings and frameworks were cemented to each master abutment model using a resin luting cement (RelyX ARC, 3M ESPE, St. Paul, MN, USA) according to manufacturer's specifications without any adjustment on the inside. Cemented pieces were immediately subjected to a fixed load of $2 \mathrm{kgf}$, and excess cement paste was removed. After embedding cemented copings and frameworks with their respective master abutment models in an acrylic resin (Palapress Vario, Heraeus Kulzer, Wehrheim, Germany), they were sectioned in the mesiodistal direction with a
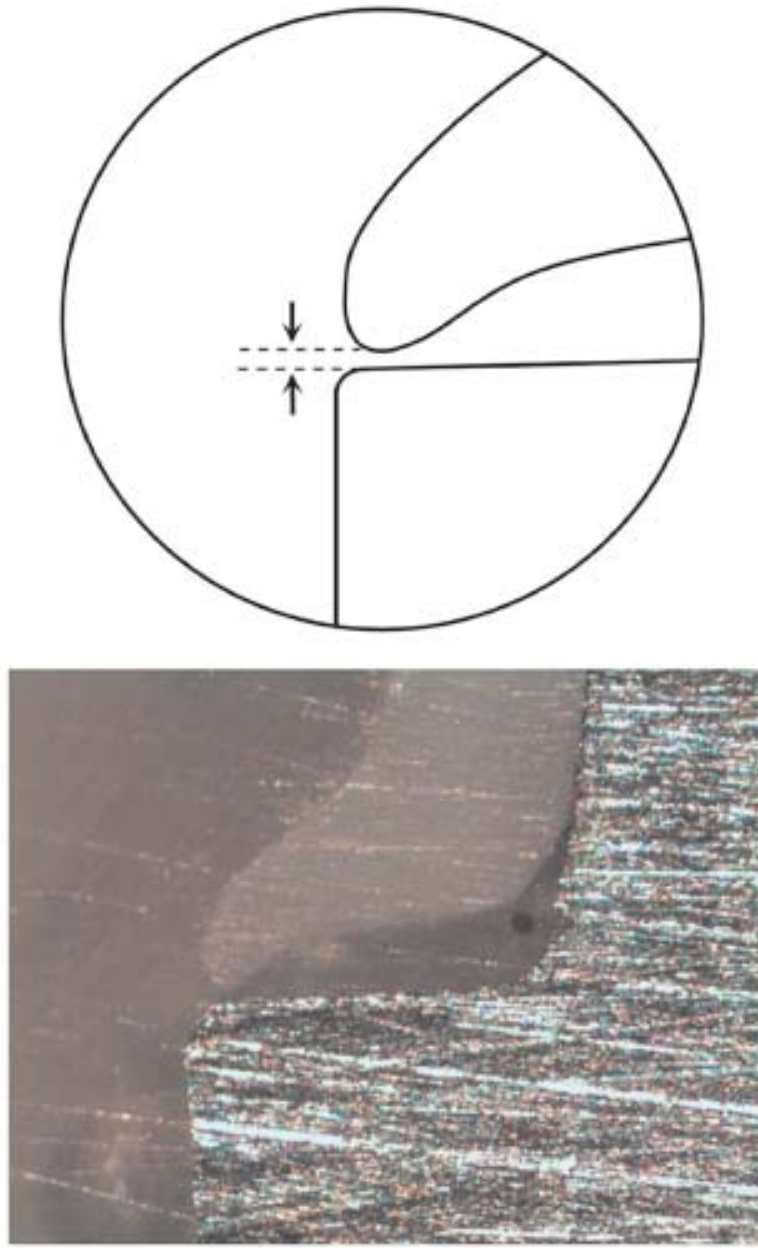

Fig 6. Marginal gap measurement. 
low-speed diamond cutting machine (Isomet \#11-4255, Buehler Ltd., Lake Bluff, IL, USA). Thickness of the cement layer was measured using a digital microscope (Moticam 2000, Shimadzu, Kyoto, Japan) at $\times 40$ magnification. Five measurement points were set for one abutment as illustrated in Fig. 5 .

Marginal gap - a parameter intended for evaluating marginal fit - was defined as the vertical distance from the internal surfaces of the copings and frameworks to the surface of the master abutment close to the finish line, as illustrated in Fig. 6. Three copings and frameworks of each type of crown/bridge framework were examined.

Statistical analysis was performed to compare the marginal and internal fit of different models at 0.05 level of significance using Tukey's test.

\section{RESULTS}

Figure 7 summarizes the mean values and standard deviations of the marginal gaps and thicknesses of the cement layer at each measuring point.

With the single-crown coping, mean value of the marginal gap (points 1 and 5) was $3.6 \mu \mathrm{m}$ (SD: \pm 5.8 $\mu \mathrm{m})$. As for the thickness of the cement layer, mean values at the axial surface (points 2 and 4 ) and occlusal surface were $50.9 \mu \mathrm{m}(\mathrm{SD}: \pm 1.1 \mu \mathrm{m})$ and 101.7 $\mu \mathrm{m}$ (SD: $\pm 9.5 \mu \mathrm{m})$ respectively.

With three-unit bridge framework (APA), mean values of the marginal gap at non-pontic side (points 1 and 10) and pontic side (points 5 and 6) were 4.2 $\mu \mathrm{m}$ (SD: $\pm 7.2 \mu \mathrm{m})$ and $43.2 \mu \mathrm{m}$ (SD: $\pm 8.7 \mu \mathrm{m})$ respectively. As for the thickness of the cement layer, mean values at the axial surface of the non-pontic side (points 2 and 9) and that of the pontic side (points 4 and 7) were $10.9 \mu \mathrm{m}$ (SD: $\pm 9.5 \mu \mathrm{m})$ and $118.7 \mu \mathrm{m}$ (SD: $\pm 6.3 \mu \mathrm{m}$ ) respectively. At the occlusal surface (points 3 and 8), the mean value of the thickness of the cement layer was $136.5 \mu \mathrm{m}$ (SD: $\pm 5.8 \mu \mathrm{m})$.

With four-unit bridge framework (APPA), mean values of the marginal gap at non-pontic side (points 1 and 10) and pontic side (points 5 and 6) were $10.3 \mu \mathrm{m}$ (SD: $\pm 8.9 \mu \mathrm{m})$ and $63 \mu \mathrm{m}(\mathrm{SD}: \pm 14.8 \mu \mathrm{m})$ respectively. As for the thickness of the cement layer, mean values at the axial surface of the non-pontic side (points 2 and 9) and that of the pontic side (points 4 and 7) were $9 \mu \mathrm{m}(\mathrm{SD}: \pm 4.9 \mu \mathrm{m})$ and $115 \mu \mathrm{m}$ (SD: \pm 13.5 $\mu \mathrm{m})$ respectively. As for the thickness of the cement layer, mean value at the occlusal surface (points 3 and 8) was $146.5 \mu \mathrm{m}$ (SD: $\pm 12.5 \mu \mathrm{m})$.

With five-unit bridge framework $\left(\mathrm{A}_{1} \mathrm{P}_{1} \mathrm{~A}_{2} \mathrm{P}_{2} \mathrm{~A}_{3}\right)$, mean values of the marginal gap at non-pontic side (points 1 and 15) was $12.8 \mu \mathrm{m}$ (SD: $\pm 9 \mu \mathrm{m}$ ). As for the thickness of the cement layer, mean values at the
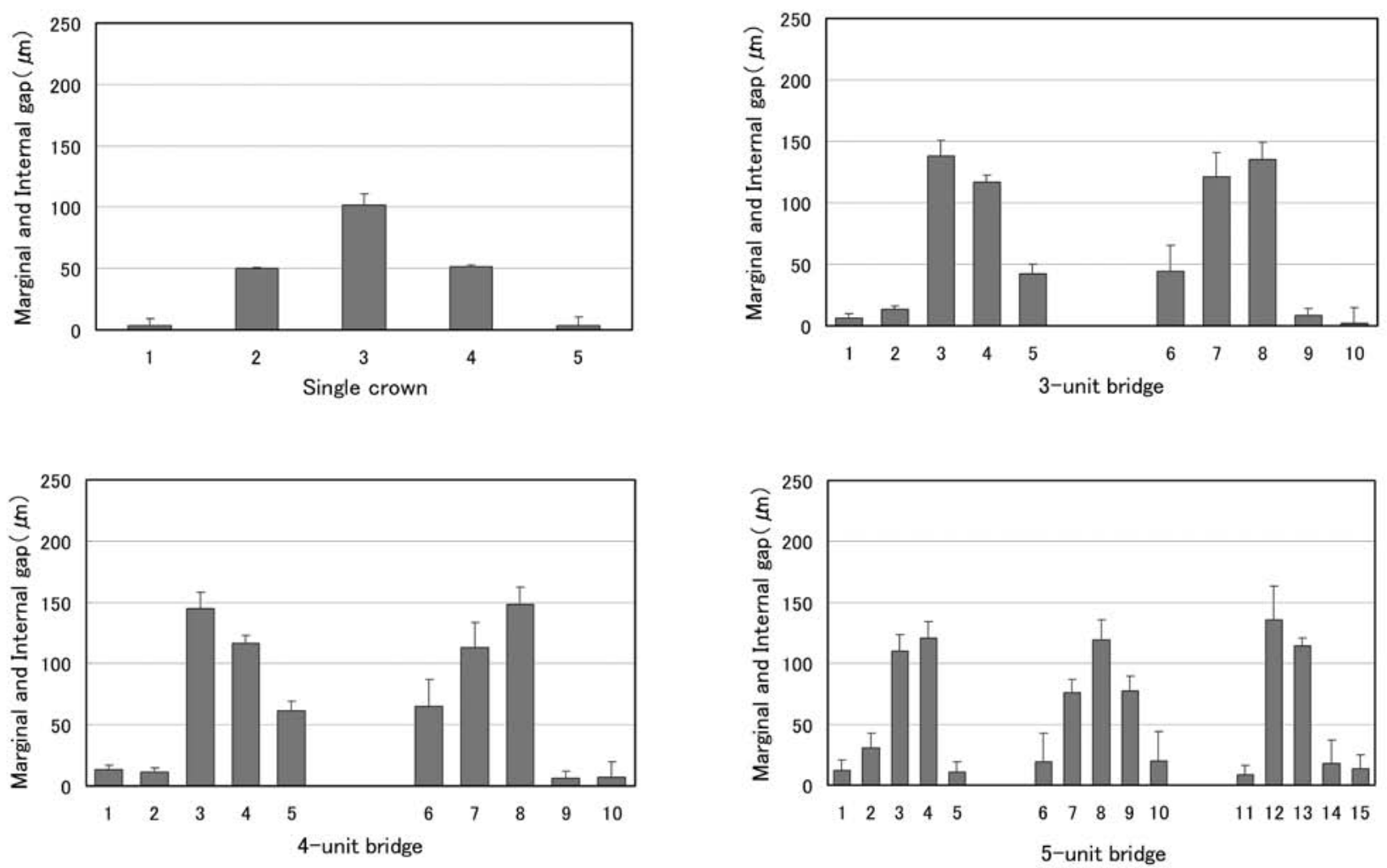

Fig 7. Summary of mean values and standard deviations at designated measurement points. 
axial surface of the non-pontic side (points 2 and 14) was $24.2 \mu \mathrm{m}$ (SD: $\pm 16.2 \mu \mathrm{m})$, while that at the occlusal surface (points 3 and 13) was $112.4 \mu \mathrm{m}$ (SD: \pm 9.5 $\mu \mathrm{m})$. For the pontic side, mean value of the thickness of the cement layer on the axial surface (points 4 and 12) was $128.1 \mu \mathrm{m}$ (SD: $\pm 21.1 \mu \mathrm{m})$, while mean value of the marginal gap (points 5 and 11) was $9.5 \mu \mathrm{m}$ (SD: $\pm 7.3 \mu \mathrm{m})$. For the coping at the center of the five-unit bridge, the average marginal gap (points 6 and 10) was $19.4 \mu \mathrm{m}$ (SD: $\pm 21.3 \mu \mathrm{m})$. In terms of the thicknesses of the cement layer, mean values at the axial surface (points 7 and 9) and occlusal surface (point 8) were $76.7 \mu \mathrm{m}(\mathrm{SD}: \pm 10.3 \mu \mathrm{m})$ and $119 \mu \mathrm{m}(\mathrm{SD}: \pm 16.4$ $\mu \mathrm{m})$ respectively.

There were no significant differences in the mean values of the marginal gap at non-pontic side among the single-crown coping, three-unit bridge, four-unit bridge, and five-unit bridge frameworks $(\mathrm{P}<0.05)$. However, in terms of marginal gap and thickness of the cement layer on the axial surface of the pontic side as well as marginal gaps of non-pontic side, the 3unit bridge and 4-unit bridge frameworks showed significant differences $(\mathrm{P}<0.05)$. As for the 5 -unit bridge framework, no significant differences in marginal gap were observed between the pontic and non-pontic sides.

\section{DISCUSSION}

Since 1990, we had launched into the research and development of the CAD/CAM system to fabricate prostheses ${ }^{17)}$. Through this effort, we succeeded in developing a software to automatically design an optimally shaped and structured crown. Subsequently, an initial prototype of a compact CAD/CAM machine was announced in 1994. It consisted of a small laser displacement gage and a milling device, and was able to perform both measurement and processing tasks in the same chamber. This device was probably the world's first integrated dental CAD/CAM device ${ }^{18,19)}$. Following further efforts of modification and improvement in both hardware and software, this device was marketed in Japan in 1999 under the product name, DECSY ${ }^{\circledR}$.

Research and development on DECSY ${ }^{\circledR}$ continued unabated. In 2003, DECSY Scan ${ }^{\circledR}$ - a small measuring device - was launched. This system uses a line laser beam and a CCD camera that allow high-speed, high-precision measurements. Projection of the line laser beam and imaging with the CCD camera are performed at an angle. As such, measurements take place as the model itself is rotated, thereby drastically improving the precision of margin measurements.

Owing to increasing concerns about metal allergy coupled with an increasing demand for improved esthetics, ceramics have become a material of choice for bridge frameworks. Among the ceramic materials, zirconia ceramics (especially partially stabilized zirconia with yttria) have an upperhand advantage of greater fracture toughness ${ }^{20)}$. However, the shaping and machining of this material is difficult in a conventional dental laboratory. As such, new technologies such as CAD/CAM processing using networks and industrial facilities have since sprouted. For example, with the Procera ${ }^{\circledR}$ system, outsourcing in specialized dental technologies was made possible via networks. Indeed, this system had a great impact in the field of dental technologies worldwide.

Currently, a network is supported by a number of systems for the fabrication of zirconia frameworks. In dental laboratories nowadays, only a small measuring device is installed. Once a model is measured, data are sent to a processing center via the Internet. A processing center is a special factory for medical devices. Using large, computer-controlled processing machines, the processing center more efficiently produces betterfitting frameworks and delivers them to the laboratory that orders them. In the laboratory, esthetic restorations are completed by baking specific porcelain on the framework. Therefore, the use of this network system offers multiple benefits: reduces labor by eliminating the need for individual CAD/CAM equipment, as well as centralizes the control of product quality and production processes.

As mentioned in the INTRODUCTION section, three types of zirconia blanks are currently available. A popular method involves the use of green-stage blanks and raw-stage blanks because of easy machining, but must be followed by post-machining sintering. A newly developed CAD/CAM system, KATANA ${ }^{\circledR}$, uses raw-stage blanks. However, to date, the effects of post-machining sintering on the marginal and internal fit of frameworks have not been evaluated. Therefore, to the end of thoroughly evaluating the fit of zirconia copings and frameworks fabricated by $\mathrm{KATANA}^{\circledR}$, standardized models of single-crown coping and bridge frameworks ( $\mathrm{A}, \mathrm{APA}, \mathrm{APPA}$, and $\mathrm{A}_{1} \mathrm{P}_{1} \mathrm{~A}_{2} \mathrm{P}_{2} \mathrm{~A}_{3}$ ) were prepared in this study.

In this study, the amount of cement space could be determined independently when the coping and frameworks were designed. As such, no cement space was used for the margin and $50 \mu \mathrm{m}$ was used for the axial and occlusal surfaces of the abutment. it was found that the marginal gap and thickness of the cement layer on the axial surface of single-crown coping were almost the same as those of the designed cement space. These values were excellent when compared with those previously reported using other CAD/CAM systems ${ }^{21,22)}$. The excellent fit obtained herein in this study, we believed, could be attributed to the laser scanning system of KATANA ${ }^{\circledR}$, which accurately measured the margin line of the stone model. As a result, the shrinkage adjustment of milled zirconia blanks during the CAD process was satisfactory.

On the other hand, the mean value of the thickness 
of cement layer at the occlusal surface was larger than the set value. For this large discrepancy, we believed it could be attributed to the anisotropic shrinkage of zirconia blanks subjected to post-machining sintering. As a result, sintering shrinkage in the tooth axis was smaller than that in the horizontal axis. Due to this shrinkage property, either uniform zirconia blanks need to be prepared for post-machining sintering or that dimensional changes of frameworks need to be corrected/adjusted in view of the anisotropic shrinkage of the blanks.

With the three-unit (APA) and four-unit (APPA) bridge frameworks prepared in this study, the mean values of the marginal gap were also excellent compared with other CAD/CAM systems ${ }^{15,16)}$. However, marginal gaps on the pontic side were significantly larger than those on the non-pontic side. When the distance between abutments became larger, the discrepancy between the pontic and non-pontic sides also became larger. Similarly, the mean values of the thickness of cement layer on the axial surface of pontic side were larger than those of the non-pontic side. Comparing the data between single-crown coping and bridge frameworks, the shrinkage of the pontic during post-machining sintering obviously influenced adaptability. Nonetheless, the effects of the current system $\left(\right.$ KATANA $\left.^{\circledR}\right)$ on the marginal and internal fit of threeunit and four-unit bridge frameworks were found to be within clinical acceptance.

With the five-unit bridge framework $\left(\mathrm{A}_{1} \mathrm{P}_{1} \mathrm{~A}_{2} \mathrm{P}_{2} \mathrm{~A}_{3}\right)$ prepared in this study, it was intended to evaluate the effect of center abutment $\left(\mathrm{A}_{2}\right)$ on the total marginal fit of the framework. Interestingly, marginal gaps on the pontic sides of $A_{1}$ and $A_{3}$ were significantly smaller than those on the non-pontic sides of $A_{1}$ and $A_{3}$. Furthermore, the marginal gaps of $\mathrm{A}_{2}$ on both pontic sides were also significantly smaller than those of APA and APPA. Apparently, therefore, the marginal adaptability of $\mathrm{A}_{1} \mathrm{P}_{1} \mathrm{~A}_{2} \mathrm{P}_{2} \mathrm{~A}_{3}$ was significantly improved.

It is noteworthy that distortion of frameworks during post-machining sintering might have produced bending stress on the frameworks of APA and APPA. As a result, axes of the abutment portion of these frameworks inclined, leading to a discrepancy in the marginal gap between the pontic and non-pontic sides. However, in the $\mathrm{A}_{1} \mathrm{P}_{1} \mathrm{~A}_{2} \mathrm{P}_{2} \mathrm{~A}_{3}$, framework, the distortion of $\mathrm{A}_{2}$ caused by the shrinkage of $\mathrm{P}_{1}$ was compensated by the distortion caused by the shrinkage of $\mathrm{P}_{2}$. Consequently, the axis of the abutment portion $\left(\mathrm{A}_{2}\right)$ of the framework was kept vertical, thereby resulting in an excellent marginal fit for $\mathrm{A}_{2}$. Thus, findings of this study clearly showed that framework design was important to preventing distortion of long frameworks during post-machining sintering.

\section{CONCLUSIONS}

Single-crown coping (A: abutment), three-unit bridge framework (APA, P: pontic), four-unit bridge framework (APPA), and five-unit bridge framework $\left(\mathrm{A}_{1} \mathrm{P}_{1} \mathrm{~A}_{2} \mathrm{P}_{2} \mathrm{~A}_{3}\right)$ were fabricated with zirconia raw-stage blanks using a commercial CAD/CAM system (Kataba ${ }^{\circledR}$ ). The effects of post-machining sintering on the marginal and internal fit of the coping and frameworks were evaluated and summarized as follows:

1. Fit of the single-crown coping (A) was excellent except for the discrepancy at the occlusal surface.

2. Marginal and internal fit of APA and APPA frameworks were within clinical acceptance. However, marginal gap and thickness of the cement layer on the axial surface of the pontic side of APA and APPA were significantly higher than those of the non-pontic side. These differences arose from the sintering shrinkage of the pontic and distortion of the framework during post-machining sintering.

3. Marginal adaptability of $\mathrm{A}_{1} \mathrm{P}_{1} \mathrm{~A}_{2} \mathrm{P}_{2} \mathrm{~A}_{3}$ framework was superior to those of APA and APPA because the center abutment supported the framework to prevent distortion.

4. To guarantee good fit of CAD/CAM-fabricated zirconia frameworks, it was mandatory to perform delicate dimensional adjustments during the CAD process as well as implement good framework design guidelines to prevent the distortion of long frameworks.

\section{ACKNOWLEDGEMENTS}

The authors would like to thank Dr. K. Ban and Noritake Dental Supply Co. Ltd. for fabricating the zirconia frameworks. This study was supported in part by a Grant-in-aid for Scientific Research from the Japan Society for the Promotion of Science (C) (No. 18592142).

\section{REFERENCES}

1) Magne P, Belser U. Esthetic improvements and in vitro testing of In-Ceram Alumina and Spinell ceramic. Int J Prosthodont 1997; 10: 459-466.

2) Christensen GJ. Ceramic vs. porcelain-fused-tometal crowns: give your patients a choice. J Am Dent Assoc 1994; 125: 311-312.

3) Heffernan MJ, Aquilino SA, Diaz-Arnold AM, Haselton DR, Stanford CM, Vargas MA. Relative translucency of six all-ceramic systems. Part I: Core materials. J Prosthet Dent 2002; 88: 4-9.

4) Heffernan MJ, Aquilino SA, Diaz-Arnold AM, Haselton DR, Stanford CM, Vargas MA. Relative translucency of six all-ceramic systems. Part II: Core and veneer materials. J Prosthet Dent 2002; 88: 10- 
15.

5) Moller H. Dental gold alloys and contact allergy. Contact Derm 2002; 47: 63-66.

6) Shepard FE, Moon PC, Grant GC, Fretwell LD. Allergic contact stomatitis from a gold alloy - fixed partial denture. J Am Dent Assoc 1983; 106: 198-199.

7) Blatz MB. Long-term clinical success of all-ceramic posterior restorations. Quintessence Int 2002; 33: 415-426.

8) Christensen GJ. Porcelain-fused-to-metal vs. nonmetal crowns. J Am Dent Assoc 1999; 130: 409-411.

9) Suttor D, Bunke K, Hoescheler S, Hauptmann H, Hertlein G. LAVA - the system for all-ceramic $\mathrm{ZrO}_{2}$ crown and bridge frameworks. Int J Comput Dent 2001; 3: 195-206.

10) Sundh A, Sjogren G. Fracture resistance of allceramic zirconia bridges with differing phase stabilizers and quality of sintering. Dent Mater 2006; 22: 778-784.

11) Okutan M, Heydecke G, Butz F, Strub JR. Fracture load and marginal fit of shrinkage-free $\mathrm{ZrSiO}_{4}$ all-ceramic crowns after chewing simulation. J Oral Rehabil 2006; 33: 827-832.

12) Felton DA, Kanoy BE, Bayne SC, Wirthman GP. Effect of in vivo crown margin discrepancies on periodontal health. J Prosthet Dent 1991; 65: 375-364.

13) Tuntiprawon M, Wilson PR. The effect of cement thickness on the fracture strength of all-ceramic crowns. Aust Dent J 1995; 40: 17-21.

14) Hertlein G, Franke R, Wastian C, Watzek K. Marginal fit of zirconia restorations with three/four abut- ment teeth. IADR 2005, Baltimore, Abstract 1764.

15) Reich S, Wichmann M, Nkenke E, Proeschel P. Clinical fit of all-ceramic three-unit fixed partial dentures, generated with three different CAD/CAM systems. Eur J Oral Sci 2005; 113: 174-179.

16) Tinschert J, Natt G, Mautsch W, Spiekermann H, Anusavice KJ. Marginal fit of alumina- and zirconiabased fixed partial dentures produced by a CAD/CAM system. Oper Dent 2001; 26: 367-374.

17) Miyazaki T, Hotta Y, Suzuki E, Miyaji T, Takahashi H, Furuya R, et al. An approach to the dental CAD/ CAM using the electric discharge machining. (Part 1) Measurement of coronal figure, computer graphics and CAD procedure. Showa Shigakkai Zasshi 1991; 11: 65-69.

18) Hotta Y, Miyazaki T, Fujiwara T, Tomita S, Shinya A, Sugai Y, et al. Durability of tungsten carbide burs for the fabrication of titanium crowns using dental CAD/ CAM. Dent Mater J 2004; 23: 190-196.

19) Miyazaki T, Hotta Y, Kunii J, Fujiwara T. Current status and future prospects of a dental CAD/CAM system used in crown-bridge restorations. Dentistry in Japan 2007; 43: 189-194.

20) Piconi C, Maccauro G. Zirconia as a ceramic biomaterial. Biomaterials 1999; 20: 1-25.

21) Bindl A, Mormann WH. Marginal and internal fit of all-ceramic CAD/CAM crown-copings on chamfer preparations. J Oral Rehabil 2005; 32: 441-447.

22) Coli P, Karlsson S. Fit of a new pressure-sintered zirconium dioxide coping. Int J Prosthodont 2004; 17: 59-64. 